\title{
De la era de Gutenberg a la era de Berners Lee: adaptación, evolución y responsabilidad social
} From the Time of Guttenberg to the Time of Berners Lee: Adaptation, Evolution and Social Responsibility

Marian Núñez Cansado

Doctora en Ciencias de la Información por la UCM y profesora de la

Universidad de Valladolid

mariannc11@yahoo.es

Rocío Collado Alonso

Profesora de la Universidad

de Valladolid

rcollado@hmca.uva.es
Núñez, M., Collado, R. (2013). De la era Gutenberg a la era Berners Lee: adaptación, evolución

y responsabilidad social. Revista Internacional de Investigación en Comunicación aDResearch ESIC. № 8 Vol 8. Segundo semestre, junlio-diciembre 2013. Págs. 96 a 109 DOI: 10.7263/ADRESIC.008.005 
Clasificación JEL:

M3, M37

Palabras clave:

Publicidad, Medios de Comunicación, Neurociencia,

Marketing

La publicidad está unida a la historia, está presente como resultado de la evolución económica, comercial, tecnológica, cultural. Tal y como afirma Watzlawick, a comunicar, sobretodo y ante todo. No podemos dejar de comunicar y cada avance tecnológico nos proporciona herramientas más eficaces para poder llevar a cabo esta actividad innata de la especie humana.

Los tiempos que vivimos nos obligan a redefinir los modelos de comunicación y partir de un concepto nuevo de consumidor que se enfrenta a los mensajes publicitarios de forma crítica y activa y que dispone de una amplia red para compartir conocimientos y contenidos mediante una comunicación horizontal prácticamente sin barreras.

Las estrategias publicitarias y los mensajes dan un giro y por ello, tendremos que volver a definir el concepto de publicidad y las actividades que forman parte de este tipo de comunicación. Qué es publicidad, qué son las relaciones públicas, el marketing de guerrilla..., cuáles son las fronteras de estas actividades.

Adaptarse y evolucionar para proporcionar a las marcas y empresas una mayor cobertura y una mayor eficacia.

ABSTRACT

JEL Classification

JEL: M3, M37

Key words:

Advertising,

Communication

Media,

Neuroscience,

Marketing.
Advertising is joined to history; it is present due to economic, commercial, technological and cultural evolution. As stated by Watzlawick, to communicate, above and before everything else. We cannot stop communicating and each technological advance gives us more efficient tools to carry out this activity, innate to the human species.

The time we live in forces us to redefine the communication models based on a new consumer concept that confronts advertising messages actively and critically, and that has available a wide network to share knowledge and contents through horizontal communication that has practically no barriers.

The strategies and advertising messages take a twist and because of this, we have to redefine the concept of advertising and the activities that make up this type of communication. What is advertising, what are public relations, guerrilla marketing..., what are the boundaries of these activities?. Adapting and evolving to offer brands and companies greater coverage with greater efficiency. 


\section{Desde los comienzos: adaptación y evolución}

Hace algo más de unos 14 millones de años, los primates vivían cómodamente en los árboles, alimentados de frutos, prácticamente sin predadores. Sin embargo, las cosas empezaron a cambiar. Muchos primates se vieron obligados a abandonar su hábitat arbóreo. Quizás su vida fácil condujo a la superpoblación y algunos grupos fueron expulsados de los bosques hacia las sabanas, un ambiente hostil para unos animales incapaces de digerir hierba y pobremente dotados para la caza. De esta época datan los restos más antiguos, el Ramapithecus, que pobló buena parte de Europa, África y Asia. En su esqueleto se advierten vestigios de posición erguida. Podemos suponer que estos primates desplazados compensaron su debilidad formando manadas, al estilo de los mamíferos cazadores. La postura erguida favorecía que cada miembro de la manada pudiera mantener contacto visual con los restantes, de modo que podían avisarse más eficientemente si detectaban algún peligro. Así pues, la selección natural favoreció a los individuos mejor dotados para la "incómoda" postura erguida.

Desde hace unos 6 millones de años, fueron apareciendo en el este de África varias especies de homínidos agrupadas por los biólogos bajo el género Australopithecus. De forma progresiva las distintas especies de Australopithecus fueron adquiriendo la postura erguida como habitual y su capacidad craneana -aun siendo pequeña en comparación con la del hombre actual- fue aumentando. Lo que estaba sucediendo era que los homínidos compensaban sus pocas dotes de supervivencia con un incremento de sus habilidades: la postura erguida hizo que ya no necesitaran sus manos para caminar, y pronto aprendieron a usarlas para matar presas pequeñas con piedras, potenciaron su agilidad, su capacidad de comunicación y su capacidad de observación, y todo ello se corresponde fisiológicamente con un incremento de la complejidad neuronal de su corteza cerebral.

Las condiciones de vida llevaron a una nueva evolución génica: la maduración retardada. En un momento dado, aparecieron homínidos con un defecto genético: nacían prematuramente y su crecimiento era demasiado lento. A primera vista, esto era un grave inconveniente: con el tiempo, las crías llegaron a nacer sin pelo, sin dientes, con la caja craneal todavía sin soldar, sin capacidad de andar, y tardaban un tiempo desmesurado en valerse por sí mismas. Pensarían entonces nuestros antecesores: ¿el hombre se está extinguiendo? Es la muerte de la especie.

Nada más lejos de la realidad, resultó que las nuevas crías mostraron un alto grado de curiosidad durante su relativamente breve período juvenil. Los homínidos conservaron su interés por observar y aprender durante toda su vida, y esto los hizo notablemente más inteligentes. Ésta es la razón por la que la selección natural estimuló la maduración retardada, que se fue agudizando a lo largo de las sucesivas especies de homínidos, que aprendieron a tallar la piedra, a hacerla punzante y cortante y dispusieron de armas más eficaces para la caza.

La nuevas eras glaciares llevaron a un empeoramiento de la caza y los homínidos fueron adaptándose a las nuevas circunstancias, aprendimos a manejar el fuego, a cultivar la tierra, a domesticar animales. Sobrevivimos.

Si tuviera que elegir una de las estrategias más acuciantes que ha ido utilizando el hombre durante estos millones de años diría que es la adaptación: adaptación a cambios climáticos, sociales, políticos, culturales, económicos. Esta capacidad 
innata en el hombre nos llevó a descubrir el fuego, punto de inflexión en la historia de la evolución del hombre y supimos sacar partido de él: lo utilizamos para calentarnos, alimentarnos, para matar: es el gran descubrimiento de la historia de la humanidad, o quizás no.

¿Tal vez sea Internet? ¿Las nuevas redes sociales? ¿Podrá el hombre también adaptarse a esta nueva circunstancia y a las actividades inherentes a él como la comunicación y la persuasión? Mucho me temo que así será, la adaptación no supuso antaño la extinción sino un nuevo renacer, la especie humana se adaptó, cambió sus parámetros, creció y no sólo sobrevivió, sino que mejoró en cada paso. Cada uno de los inconvenientes forzó a la humanidad a cambios no sólo de actitudes, valores, sino a cambios más profundos basados en su genoma que nos han sido legados generación tras generación.

Evolución es la palabra que describe nuestra historia. Según la RAE evolucionar es desenvolverse, desarrollarse, pasar de un estado a otro, mudar conductas o actitudes. La evolución no lleva implícito el término muerte, sino el término cambio, mejora. Todas y cada una de las actividades, actitudes y comportamientos propios de hombre han sufrido esta evolución.

\section{La comunicación}

Según el enfoque evolucionista, uno de los elementos claves para poder llegar a entender al ser humano en su concepción actual, parte de la premisa de que la capacidad humana para la cultura ha surgido mediante selección natural por los beneficios adaptativos que proporcionó a nuestros ancestros. Esa capacidad para la cultura incluye habilidades cognitivas para la representación simbólica, el lenguaje, el pensamiento abstracto, el aprendizaje social, así como habili- dades físicas para el habla y las manifestaciones culturales y como no la comunicación, y con ella, la publicidad.

La publicidad es también una actividad inherente al hombre, y por tanto, también una actividad sujeta a esta evolución. La publicidad es una forma de comunicación persuasiva que actúa en las actitudes humanas con el fin de lograr una predisposición favorable hacia la introducción, el mantenimiento y el aumento del uso o consumo de un producto o servicio cualquiera. Dos conceptos básicos que se entrelazan en la definición de publicidad: persuasión y comunicación.

La persuasión y la comunicación unidas en su esencia misma. Así, Aristóteles dejó muy claramente asentado que la meta principal de la comunicación es la persuasión, es decir, el intento que hace el orador de llevar a los demás a tener su mismo punto de vista. Persuasión y comunicación formando una simbiosis inquebrantable.

Según Watzlawick y sus colaboradores (Paul Watzlawick, 1993) ${ }^{1}$, del mismo modo que uno no puede permanecer sin comportarse, y dado que toda situación de interacción tiene un valor de mensaje, por mucho que uno lo intente, no puede dejar de comunicarse. Siempre que esté presente otra persona en el mismo campo perceptual, cualquier actividad, e incluso, la inactividad, las palabras o el silencio, tienen valor de mensaje, influyen en los demás, quienes a su vez, no pueden dejar de responder a tales comunicaciones y, por tanto, también comunican.

El ser humano tal y como lo definió Aristóteles hace más de dos mil años es un zoom politikon, un animal social por naturaleza y, como añade el axioma más clásico de la comunicación,

1 Paul Watzlawick, Janet Bavelas y Don D. Jackson, Teoría De La Comunicación Humana Editorial Herder, 1993 
un animal que en la relación social es incapaz de no comunicarse.

Como afirmaba Gonzalo Musitu la comunicación se produce siempre ${ }^{2}$ (Gonzalo Musitu y otros, 1993). Para que esto sea claro, es preciso entender que comunicación es sinónimo de comportamiento, en la medida que todo lo que hacen las personas en presencia de otros tiene el valor de un mensaje. Cada comportamiento, consciente o no, intencional o no, puede ser interpretado y es, por tanto, un mensaje. Así, las nuevas estrategias de marketing están encaminadas a transmitir desde el comportamiento que cualquier actividad del ser humano puede ser traducida en comunicación y convertida en publicidad.

La persuasión y la comunicación son dos comportamientos inseparables innatos en la especie humana que han ido por lo tanto de la mano a lo largo de la historia de la humanidad, siendo sus objetivos y fines adecuados a las necesidades de cada época o circunstancia histórica.

La aparición de nuevos soportes y nuevos medios exige al ser humano una nueva adaptación en una de sus capacidades más distintivas: la comunicación. Esta adaptación constituirá un nuevo aprendizaje único que supondrá en la gran mayoría de los casos una mejora no sólo para la publicidad o la comunicación sino para la adaptación más adecuada de la especie.

\section{Comienzos de la publicidad}

La prehistoria de la publicidad nos lleva hasta la ciudad de Tebas en el año 3000 a.c., allí encontramos el primer anuncio: se trata de un cartel hecho de tela donde se ofrecía una moneda de oro a cambio de la captura de un esclavo:

\footnotetext{
2 Gonzalo Musitu y otros, Psicología De La Comunicación Humana, Lumen 1993, Pág. 52
}

"Habiendo huido el esclavo Shen de su patrono Hapu, el tejedor, este invita a todos los buenos ciudadanos de Tebas a encontrarle. Es hitita de cinco pies de alto, de robusta complexión y ojos castaños, a quien lo devuelva a la tienda de Hapu, el tejedor, donde tejen las más bellas telas al gusto de cada uno, entregará una pieza de oro"3

Tanto griegos como egipcios y babilonios usaban tablillas de barro y arcilla para anunciar productos y servicios, además los griegos contaban con pregoneros que anunciaban la llegada de los barcos con cargamentos de vino, especias y metales y el pregonero iba acompañado de un músico que lo mantenía en el tono adecuado. La figura del pregonero se convirtió años más tarde en muchos países europeos en el medio más común de anuncios públicos.

Los mercaderes romanos también sabían de la necesidad de la publicidad. En algunas excavaciones arqueológicas como las de la ciudad de Pompeya, se pudieron encontrar las primeras manifestaciones de lo que hoy en día definimos como publicidad exterior, se trata de anuncios en las paredes o letreros en piedra o terracota donde se anunciaba lo que se vendía en las tiendas: una hilera de jamones para una carnicería, una bota para un zapatero, una vaca para una lechería. Un anuncio desenterrado en Roma informa sobre un terreno puesto a la venta y otro encontrado en una pared de Pompeya anuncia una taberna situada en otra ciudad.

Tablillas de barro, arcilla, paredes, letreros en piedra, constituían la tecnología del momento y eran utilizadas para lograr persuadir a los sujetos acerca de la adquisición de un producto o de la visita a un determinado lugar; en definitiva: ventas. Ventas que suponían la supervivencia de un negocio y de la economía familiar.

3 Museo Británico de Londres. Cartel de tela: Tebas año 3000ac 
A medida que los años fueron pasando, los avances tecnológicos en esta materia no fueron muy apreciables, de modo que el papel de la publicidad exterior seguía mantenido un puesto muy relevante en épocas como la Edad Media donde la tónica general la marcaba el analfabetismo de su población. Los mesoneros competían entre sí para diseñar carteles atractivos con el fin de identificarlos con su mesón y atraerles hacia su negocio. La construcción de estas imágenes identificativas irían apareciendo de una forma cada vez más frecuente en los reclamos escritos donde se indicaban iglesias, servicios, y que podemos considerar fueron el antecedente de lo que hoy conocemos como identidad corporativa. Del mismo modo que las enseñas, colocadas en la entrada de las calles o en las viviendas, podrían considerarse el antecedente de los logotipos actuales.

\section{La adolescencia La gran revolución: la galaxia de Gutenberg}

El avance más relevante en la tecnología utilizada por la comunicación humana no tiene lugar hasta el año 1438. En este año Gutenberg desarrolla la imprenta dando lugar a la época definida por McLuhan como "la galaxia Gutenberg". El impacto de este nuevo avance tecnológico fue tremendo, provocó una verdadera revolución en la cultura del mundo. El conocimiento dejó de ser patrimonio de una élite y se extendió a extractos de la población de forma inimaginable hasta el momento. Con la imprenta llegó la nueva era de la comunicación de masas, la aparición de nuevos métodos de comunicación, llevó a nuevas formas de comunicarnos, de entendernos y de informarnos. La imprenta fue el principio del fin del analfabetismo. Logró cambiar el mundo, permitió compartir el conocimiento y trascender el tiempo y el espacio a una velocidad en absoluto pensada hasta entonces.

Forzó el cambio de reglas gramaticales - ortográficas, dejando atrás una larga tradición de oralidad, empieza a escribirse tal y como se hablaba. Nacieron nuevas formas de comunicación que permitieron compartir conocimientos y redefinir el concepto de fronteras culturales. Surgieron nuevos conceptos, como la modernidad, la noción del hombre como individuo pensante e independiente de Dios, la aparición de la ciencia compartida y pública.

La transcendencia social, política y económica de este nuevo avance tecnológico sin precedentes supuso una nueva definición del mundo sentando la base de una reforma sociocultural no conocida desde el descubrimiento del fuego.

Nuevos medios de comunicación, nuevas formas de trascender el tiempo y el espacio, velocidades inimaginables, cambios de reglas gramaticales - ortográficas, nuevas definiciones de fronteras culturales, nuevas formas de compartir el conocimiento... Estos conceptos parecen familiares y muy actuales.

\section{La madurez Tiempos modernos: la llegada de la Era de Berners Lee}

Los avances tecnológicos han sido en las últimas décadas imparables, destacaremos dos que marcarán un cambio sustancial en la comunicación de masas: de un lado Internet, de otro, las técnicas de neuroimagen. Ambas supondrán cambios en las estrategias, en las reglas del juego, en evaluaciones y análisis, en los lenguajes; nuevas formas de comunicación inimaginables e imprevisibles que deben hacernos cuestionar los modelos clásicos de comunicación. 
La neurociencia encuentra en los nuevos avances tecnológicos, como la tomografía axial computerizada (TAC), la resonancia magnética nuclear o la resonancia magnética funcional, nuevas formas de estudiar la estructura y la función química, farmacológica y patológica del sistema nervioso y de cómo los diferentes elementos de este sistema interaccionan y dan origen a la conducta. Las neurociencias se combinan con la psicología para crear la neurociencia cognitiva, la cual proporciona una nueva manera de entender el cerebro y la conciencia, al basarse en un estudio científico que une disciplinas tales como la neurobiología, la psicobiología o la propia psicología cognitiva. Estos nuevos avances científicos están cambiando la concepción actual sobre los procesos mentales implicados en el comportamiento y sus bases biológicas.

El papel de las emociones y el comportamiento cobran vital importancia en la neuropsicología y sus aportaciones son vitales hoy en día para el mundo del marketing. Así, la neurociencia nos ofrece un marco teórico que nos permite interpretar los resultados partiendo del conocimiento de las bases neuronales responsables de todo comportamiento.

Llevamos décadas especulando acerca del comportamiento del sujeto y las consecuencias posibles frente a comunicaciones persuasivas, ahora comenzamos a vislumbrar soluciones a muchas cuestiones que son básicas en el mundo del marketing y la publicidad.

Haremos llegado este punto, alusión a un estudio realizado por las doctoras Cristina Balanzó y Nuria Serrano ${ }^{4}$ de la Universidad Autónoma de

4 Cristina de Balanzó Bono y Nuria Serrano Abad: Fundamentos para construir un modelo de comunicación publicitaria desde la perspectiva de la neurociencia www.aeic2010malaga.org/upload/ ok/87.pdf
Barcelona. Según este estudio, tres son los avances vitales que aporta la neuropsicología y que serán relevantes en un nuevo sistema de comunicación hasta el punto de plantearnos nuevos modelos que puedan hacer frente a las teorías novedosas sobre el comportamiento del sujeto:

1. La influencia de la flexibilidad cerebral y del inconsciente

2. El funcionamiento y el rol de las emociones

3. El funcionamiento y el rol real de la memoria

\section{a. Influencia de la flexibilidad cerebral y del inconsciente}

La plasticidad, propia de un complejo sistema como nuestro cerebro, supone que poseemos un sistema de neuronas altamente cambiante y adaptable que influye directa y definitivamente en el funcionamiento de nuestros procesos cognitivos. El sujeto adulto puede aprender, modificar y adaptarse hasta el fin de sus días. La complejidad de estos procesos junto con los múltiples factores que implican la comunicación, debiera hacernos reflexionar acerca de la validez de los múltiples estudios de persuasión que se han venido produciendo durante décadas.

\section{b. Funcionamiento y rol de las emociones}

Tradicionalmente hemos vivido el enfrentamiento de emociones vs razón, la neuropsicología rompe con el debate y afirma que somos el resultado de ambos, siendo ambos elementos inseparables. Los nuevos avances brindados por Antonio Damasio ${ }^{5}$ nos ofrecen una gran oportunidad de conocer las bases neurofisiológicas de la vida humana: la formación de imágenes percibidas, los procesos memorísticos y la cuantificación y

5 Antonio Damasio: Descartes Error: Emotion, Reason and the Human Brain, Pan Macmillan, abril de 1994 
cualificación de procesos emocionales y su relación con los aspectos cognitivos.

Las emociones son vitales para los procesos cognitivos, sin las emociones, la toma de decisión racional no sería posible. Se deja atrás la era del racionalismo y se da paso a una nueva era en la que racionalismo y emociones son imprescindibles e indisociables en la esencia del ser humano.

Ahora estamos en disposición de poder afirmar que es necesaria la emoción para lograr la persuasión. Necesitamos conectar con algunas de las emociones del sujeto receptor que personifiquen la marca, el producto, el beneficio o la ventaja, para poder lograr la tan deseada persuasión que modificará las actitudes del sujeto receptor.

\section{c. Concepto de memoria}

Dos son los aspectos claves que nos aporta la nueva concepción de la memoria: de un lado, una memoria activa, y de otro, la memoria subjetiva, capaz de crear y recrear recuerdos de forma poco objetiva.

Distintas pruebas de neuroimagen aplicadas en investigaciones han podido mostrar la actividad del hipotálamo, tanto en reposo como en actividad de repaso. De tal forma que podemos pensar en el proceso memorístico como un proceso lejos de poder ser activado o desactivado a nuestro antojo, puesto que siempre se encuentra en funcionamiento.

Así lo demuestran las mediciones del hipocampo frente a sujetos que tratan de memorizar una lista y aquellos cuya misión sólo era leerlas. El hipocampo siempre está activo en ambos casos tratando de codificar la información.

De igual forma, podemos observar cómo la recuperación no es un proceso que se ajuste a estándares objetivos, más bien al contrario, la vivencia del mismo momento por parte de dos sujetos no ha de ser narrada exactamente igual en la recuperación. El sujeto participa activamente en la formación de sus recuerdos y de la recuperación de los mismos, propiciando una nueva codificación de lo recibido. Así, debemos dejar de un lado la famosa decodificación tan laureada por los modelos comunicativos y empezar a definir el proceso de almacenamiento y de significación como una nueva codificación individual y subjetiva.

El sujeto participa activamente de sus recuerdos, construye sus significados, toma decisiones basadas en las emociones y en el raciocinio. Este sujeto al que deseamos persuadir no es un sujeto nuevo, pero sí un sujeto que se adapta a las peculiaridades de su entorno. Es un sujeto que participa de la codificación, de los mensajes que recibe, un sujeto activo que forma parte de la construcción de mensajes, convirtiéndose en emisor y creador de mensajes.

De esta forma, puede recibir un mensaje publicitario, codificarlo y transformarlo en un mensaje distinto, y mediante el word of mouth o el buzz interactivo, o simplemente el mouth of mouth, hacer las veces de medio y transferir su nuevo mensaje a otros receptores. Sólo necesitaría una red social amplia para poder alcanzar una alta cobertura.

El sujeto siempre ha actuado así, ahora lo sabemos, pero hace cinco siglos no poseíamos esta cobertura para transformar al sujeto de sujeto receptor a sujeto emisor e incluso sujeto medio.

Hablamos por lo tanto, de un target activo que desea formar parte de las acciones de comunicación y que construye sus propios mensajes, un receptor que conoce las estrategias de publicidad y que se ha vuelto crítico. Ya no le divierten los mensajes publicitarios porque la saturación le ha causado hastío y aburrimiento. 
Este nuevo consumidor desea hablar de tú a tú con la marca, y pide a gritos una comunicación más horizontal, una comunicación en la que ellos mismos sean los protagonistas, serán ellos mismos los que hablen de las marcas y construyan los contenidos y los valores. Un sujeto que interactuará con la marca provocando un proceso continuo de feedback.

Un entorno cambiante requiere un nuevo papel para el consumidor en el que su interactividad, sus conocimientos de las marcas y estrategias publicitarias marcan nuevas reglas de juego que no son trabas para la publicidad, sino nuevas oportunidades, nuevas opciones de creatividad, nuevos horizontes que permitirán vender marcas y productos de forma más eficaz. Este nuevo consumidor no puede ser entendido sin la aparición de las nuevas formas de comunicación: Internet.

Momentos atrás, cuando hablábamos de la imprenta, hacíamos alusión a cambios que supusieron grandes esfuerzos por parte de la sociedad para lograr adaptarse a la nueva situación: nuevos medios de comunicación, nuevas formas de trascender el tiempo y el espacio, velocidades inimaginables, cambios de reglas gramaticales-ortográficas, nuevas definiciones de fronteras culturales, nuevas formas de compartir el conocimiento.

Hoy en día estamos reviviendo este tipo de consecuencias tras la aparición de Internet: nuevas reglas en los mensajes telefónicos, o en los e-mails, velocidades de transmisión que superan lo hasta ahora inimaginable, actualización de noticias en periódicos digitales en cuestión de minutos, intercambios de contenidos en un instante desde cualquier parte del mundo

Si la imprenta supuso la popularización de la cultura, la informática añade a esta populariza- ción la globalización de los conocimientos y un acceso prácticamente sin restricciones.

Internet ha reinventado la comunicación humana con sus páginas web 2.0, o las de reciente aparición web 3.0, la facilidad de acceso desde cualquier lugar del mundo, sin prácticamente límites, permite a sus usuarios interactuar con otros usuarios o cambiar contenidos del sitio web, ser productores de contenidos, formar parte de esa red de comunicación horizontal a la que hacíamos alusión anteriormente.

Videojuegos 3D, juegos en streaming, procesadores de seis núcleos, electricidad sin cables, gadgets de la casa conectados sin cables, pantallas LED, Internet ultrarápido, realidad aumentada, control remoto sin mandos, bits y bytes más rápidos. Parece claro que "La Galaxia de Gutenberg" ha sido sustituida por "la Galaxia de Berners Lee". Nuevas reglas gramaticales, nuevos soportes, nuevas formas de comunicarnos. De nuevo evolución y adaptación.

Estas nuevas reglas de juego se adaptan a las necesidades de nuestros consumidores, les permiten convertirse en sujetos activos que forman parte de la creación de los contenidos, que interactúan con productos marcas y sujetos. Pero, ¿se está adaptando la publicidad a estas nuevas exigencias?

El cambio de las tablillas de barro y madera a la imprenta supuso una adaptación a nuevas formas de comunicar: el emisor podía alcanzar un mayor público, y además las nuevas formas de impresión les permitían introducir imágenes más fidedignas, mensajes más largos, una publicidad más informativa y persuasiva. El cambio de la publicidad impresa a la televisión donde la imagen era realmente el elemento esencial supuso también cambios. De la prensa al cine, del 
cine a la televisión, ahora nos toca el turno de pasar a nuevas formas de comunicar en Internet.

\section{Adaptarse o morir}

Existen básicamente dos problemas a los que se enfrentan anunciantes y publicitarios en la actualidad: el primero es el hastío que muestra la población frente a los anuncios por la terrible saturación que venimos sufriendo en los últimos años, Así, mientras un adulto español ve a la semana un promedio de 642 anuncios en televisión (92 al día), un estadounidense está expuesto a 789 y un indonesio, a 728. En el otro extremo está Líbano, donde la media semanal es de 102 anuncios, 79\% menos que la cifra global ${ }^{6}$.

Un estudio realizado en España por la empresa Gallup index.asp en 2003 afirmaba que el 91,4 por ciento de los españoles considera que el volumen de anuncios en las cadenas de televisión es alto o muy alto. Un 46,4 por ciento, perciben el volumen publicitario de las distintas cadenas como algo desagradable o muy desagradable.

En una entrevista realizada al publicitario español Luis Bassat se podía oír la siguiente frase: "La saturación publicitaria acabará matando a la publicidad".

Estamos en condiciones de afirmar que la saturación publicitaria rompe los requisitos esenciales de la comunicación persuasiva, el sujeto deja de prestar atención a los mensajes, deja de recibir información, no es estimulado, no logra entrar en contacto con ninguna de sus motivaciones o necesidades, y consecuentemente, no es recordado. Esto puede peligrar el tan deseado "top of mind", que hasta hace poco estaba siendo impulsado de forma eficaz sobre todo gracias a la televisión.

6 estudio hecho en 50 países por la agencia de medios Initiative
El segundo de los problemas es la falta de credibilidad. Los receptores se han convertido en auténticos guardianes de los intereses de los consumidores, son sujetos críticos, vigilantes, con conocimientos y medios para informarse, $y$ con redes sociales que les ayudan a compartir sus descubrimientos. Son sujetos activos, expertos y selectivos.

La teoría de la respuesta cognitiva defiende que siempre que un receptor recibe un mensaje persuasivo, compara lo que la fuente dice con sus conocimientos, sentimientos y actitudes previas respecto al tema en cuestión, generando de esta manera unas "respuestas cognitivas". Estos mensajes auto-generados, especialmente en el aspecto evaluativo, son los que determinan el resultado final del mensaje persuasivo.

Si los pensamientos van en la dirección indicada por el mensaje, la persuasión puede tener lugar; si van en la dirección opuesta, no habrá persuasión o puede darse un "efecto boomerang". Los receptores no son persuadidos por la fuente o el mensaje, sino por sus propias respuestas ante lo que la fuente y el mensaje dicen. Para esta teoría es definitivo determinar qué factores influyen sobre la cantidad de estos argumentos. Uno de estos factores vitales es la credibilidad, el sujeto necesita creer, necesita empatizar con los productos, marcas, con beneficios o ventajas, pero para ello es necesario que éstos sean creíbles, que se presenten como elementos reales.

Si no es así, el sujeto desconfía y la persuasión pierde su fuerza. La publicidad ha dejado de ser creíble en muchos aspectos, el sujeto utiliza barreras psicológicas a la hora de analizar los argumentos, desconfía de las marcas y de los mensajes publicitarios.

Uno de los 10 mandamientos de Google, en concreto, el mandamiento 6 reza así: "do not be 
mean", que significa algo así como "no seas malo". Larry Page y Sergey Brin, creadores de Google, conocen muy bien a este nuevo consumidor que estamos presentando y las posibilidades de comunicación que ofrecen las redes sociales. No seas malo, no como enseñanza moral, sino porque si eres malo todo el mundo se enterará en pocos segundos y entonces estarás perdido. La cobertura que ofrecen las redes sociales junto con el perfil que muestran nuestros nuevos consumidores, nos obliga a dar un giro en nuestra forma de construir mensajes. Debemos ofrecer a nuestros receptores mensajes más creíbles, mensajes más honestos, más trasparentes. Es aquí donde la ética juega un papel vital, necesitamos ser buenas personas, transmitirles mensajes más éticos a nuestros receptores, porque de lo contrario, estos sujetos activos y pensantes pueden convertir nuestras mentiras y malas formas en el final de nuestra marca.

Actualmente la mayor parte de los países poseen un código ético que regula la publicidad en Internet. En España existe Autocontrol, sociedad sin ánimo de lucro a la que pertenecen el 90\% de los sectores que participan en la publicidad.

El Código Ético de Comercio Electrónico y Publicidad Interactiva (Confianza Online) abarca las comunicaciones comerciales y los aspectos contractuales en las transacciones comerciales con consumidores, realizadas a través de Internet y otros medios electrónicos.

A pesar de la aparición de alianzas en todos los continentes, como CONARED, la alianza de países latinoamericanos, o EASA, alianza de países europeos, en su intento por ofrecer comunicaciones publicitarias más éticas, la regulación es insuficiente. Tratamos de regular un mundo sin fronteras, sin límites físicos con medidas cuyos orígenes son fronteras y límites físicos.
Las normas españolas regulan aquellas páginas cuyo dominio se encuentre en su país, lo mismo ocurre con la regulación colombiana, mexicana... Pero lo cierto es que al sujeto le pueden llegar mensajes desde cualquier país, páginas dadas de alta en cualquier lugar del mundo.

Necesitamos por lo tanto, abrir nuestra mente y trabajar en un mundo sin fronteras para poder regular una nueva comunicación sin fronteras. Necesitamos un código ético universal a la altura de este nuevo medio de comunicación de masas. Un código ético semejante al que nos proponía el filósofo Kant, universal e inviolable.

Pero para regular la publicidad en Internet necesitamos redefinir el concepto de publicidad. Decíamos que los conocimientos de la neuropsicología y los avances de este nuevo medio de comunicación obligaban al anunciante y a las agencias a reestructurar sus prácticas. Nuestros sujetos son activos, selectivos y necesitan de una comunicación horizontal, sienten que deben formar parte de los mensajes de la construcción de la identidad de la marca. Estos sujetos están interconectados con miles de personas con esta red viral que puede llegar a cualquier parte del mundo.

Cada vez es más corriente encontrarse con empresas como la española Izo System que dedica su actividad a buscar en redes sociales los nuevos objetivos de marketing de las empresas y a realizar auditorías de calidad que llevan a cabo en blogs, páginas como Facebook, Tuenti donde los sujetos se convierten en verdaderos creadores de contenidos que hacen alusión a marcas, productos, servicios.

Son verdaderos prescriptores que pueden encumbrar o desprestigiar los productos, que pueden transmitirnos errores de comunicación, de servicio al cliente Modificar el pensamiento de 
los consumidores es más fácil si se conoce lo que realmente piensan.

Otro de los elementos claves para poder entender la nueva publicidad es la figura definida en 1998 por Burson-Marsteller: E-fluentials, grupos de responsables de la toma de opinión en línea y que tienen influencia exponencial en la elaboración y conducción de la opinión pública a través de Internet y en todo el mundo fuera de línea. Tienen el poder de afectar a millones de decisiones de compra de los consumidores a través de la palabra de boca en boca.

El efecto expansivo de este segmento de gran alcance puede hacer o romper una marca, reunir o disolver apoyo a las empresas y del consumidor, y proporcionar información sobre eventos según se desarrollan. Para las empresas y comerciantes, existe una necesidad urgente de obtener aprobación y apoyo.

Las agencias tratan de ofrecer contenidos que agraden a los sujetos y con los que puedan interactuar, se trata de lograr que sean ellos los que transmitan el mensaje, que se sientan identificados con las marcas o con los productos, que sientan que forman parte de la comunicación como sujetos activos y no pasivos, que nadie les diga lo que deben pensar porque ellos son autosuficientes para llegar a los argumentos necesarios para defender o censurar los beneficios, las ventajas.

Si además logramos inmiscuir al resto de los medios en nuestro nuevo proyecto conseguiremos alcanzar un mayor impacto, romper con la saturación publicitaria, propiciar una llamada de atención y un mejor recuerdo, con costes muy reducidos.

Es más creíble un mensaje contado por personas particulares que por marcas o empresas, $y$ lo creíble vende más.
De esta forma, las nuevas comunicaciones publicitarias dan un giro significativo, y utilizan las redes sociales para generar estos contenidos llegando al sujeto receptor de forma más amable, permitiéndoles participar en sus comunicaciones y en definitiva, en su publicidad. La configuración de la profesión publicitaria debe crear las estructuras necesarias y desarrollar las técnicas que permitan mejorar el proceso de creación y difusión de las campañas y, con ello, asegurar al máximo el logro de los objetivos de los anunciantes.

Debemos, por lo tanto, romper con el concepto clásico de comunicación publicitaria y redefinir una nueva comunicación que abarca un campo mucho más amplio y acorde a los nuevos soportes y las nuevas estructuras socioeconómicas.

La creación publicitaria supone incluso la definición del producto. Un ejemplo que puede hacer patente esta afirmación es el caso de las tiendas de golosinas Happy Pills. Una pequeña tienda de tan sólo $28 \mathrm{~m}^{2}$, situada en Barcelona en un lugar exento de centros educativos o cualquier otro negocio susceptible de atraer a los más pequeños, potencial target de una tienda de estas características.

Era una tienda abocada a su extinción. $\mathrm{M}+\mathrm{S}$ Estudios, un pequeño estudio de publicidad de Barcelona, fue contratado para llevar a cabo el diseño del local de la imagen de marca y del packaging de sus productos. Estos decidieron rediseñar el concepto de tiendas de golosinas, formar parte como decíamos antes de la creación del producto. Así, $\mathrm{M}+\mathrm{S}$ convenció al cliente para reinventar el producto. Le puso nombre y logotipo, diseñó el local, los rótulos, y el packaging, dando a los envases un sentido práctico como si de un botiquín sanitario se tratase: los hay de emergencia, de fin de semana, para cada momento del día, en envase familiar para golosos 
compulsivos. De esta forma desarrollaron la idea sobre la que nace Happy Pills: los caramelos son en realidad, pequeños bocados de felicidad. Así, hay píldoras contra los lunes, contra el precio de la vivienda, contra la dieta de la piña, contra los amigos invisibles sin imaginación o contra los domingos sin fútbol.

En realidad, lo que este pequeño estudio estaba haciendo era reinventar no sólo un concepto de su producto, sino también a los clientes habituales de este tipo de establecimientos: se trata de una tienda para adultos, a la que por supuesto, se permite la entrada de niños.
Happy Pills cuenta hoy en día con más de siete millones en resultados de búsqueda en Google, con apariciones en páginas de todos los países, fotos realizadas por un visitante extranjero y colgadas en un blog de diseño con sede en Chicago. Circulan ya por buena cantidad de webs y otros blogs de la red en todo el mundo. En dos años han abierto 5 nuevas tiendas más, y están pensando plantear la franquicia para extenderse al resto de España.

Esto es un nuevo concepto de creación publicitaria que muestra que la publicidad lejos de extinguirse, está más viva que nunca. 


\section{Bibliografía}

Aristóteles. (2003) Arte poética. Arte Retórica. Editorial Porrua. S.A.

Coronado, D. (2002) La Metáfora Del Espejo: Teoría E Historia Del Cartel Publicitario. Editorial

Damasio, A. (2005) En busca de Spinoza: neurobiología de la emoción y los sentimientos. Editorial Crítica

Damasio, A. (2006). El error de Descartes: la emoción, la razón y el cerebro humano. Editorial Crítica

Eguizábal Maza, R. (1998) Historia De La Publicidad. Editorial Plaza

Gaviria Stewart, E; Cuadrado Guirado, I; López-Sáez, M. (1998) Introducción a La Psicología Social. Editorial: Sanz y Torres
Macluan, M. (1962) The Gutenberg Galaxy: The Making of Typographic Man. Editoriañ. Routledge \& Kegan Paul. Toronto Musitu,G. (1993), Psicología De La Comunicación Humana. Lumen

Watzlawick, P; Bavelas, J; Jackson, D. (1993) Teoria De La Comunicación Humana; Editorial Herder. Documento electrónico

Balanzó, C; Serrano N.(2010) Fundamentos para construir un modelo de comunicación publicitaria desde la perspectiva de la neurociencia. b2010 http: //www.aeic2010malaga.org/upload/ok/87.pdf.

Burson-Marsteller (1998). E-fluentials. http://www.bursonmarsteller.com/Innovation_and_insights/E-Fluentials/Pages/default.aspx 